\title{
The Impact of a Pet, in This Case a Dog, on Physical Activity, Independence, Social Contacts, Health and Quality of Life of Elderly People
}

\author{
Anne Poestges, Ursula Gresser, Barbara Maria Richartz \\ Medical Faculty, Ludwig-Maximilians University of Munich, Munich, Germany \\ Email: anne@poestges.org
}

Received 13 June 2016; accepted 28 July 2016; published 31 July 2016

Copyright (C) 2016 by authors and Scientific Research Publishing Inc.

This work is licensed under the Creative Commons Attribution International License (CC BY). http://creativecommons.org/licenses/by/4.0/

\section{(c) (i) Open Access}

\begin{abstract}
In a rural area near Munich, 52 persons aged 65 years and older were interviewed in person about health and social life circumstances. Findings: Dog owners take significantly longer walks than people who do not own dogs, averaging more than 120 minutes daily $(p<0.0001)$. On average, people who do not own a dog walked 38 minutes, cat owners 17 minutes. 94\% of the dog owners were active daily compared to $14 \%$ of those who do not own a dog. Dog owners go to the doctor on average 5.3 times per year, people who do not own a dog 7.8 times. There was no difference between the two groups in regard to the use of medication. $80 \%$ would not move to a residential home for the elderly because of the dog, and $87 \%$ would want to take the dog along. $50 \%$ of the dog owners and $41 \%$ of those who do not own a dog had on average more than 3 contacts with other people, $6 \%$ of the dog owners and $23 \%$ of those who do not own a dog had less than one contact per day. $19 \%$ of the dog owners and $36 \%$ of those who do not own a dog would describe themselves as reserved in dealings with people. $71 \%$ stated that the dog had been very useful to help them overcome the loss of a person close to them. The W-5 [Wellbeing Five score] for dog owners was an average value of $75 \%$, for those who did not own a dog $71 \%$. Depression was uniformly distributed in both groups. The BMIs in both groups were similar. There was no correlation to the length of the daily walk.
\end{abstract}

\section{Keywords}

Elder People and Dog, Physical Activity and Dog, Dog Walking, Dog and Life Quality, Elder People Physical Activity 


\section{Introduction}

The subject of our survey is the impact of dog ownership on health, medical needs, physical activity, quality of life, and social contacts in elderly people.

The United Nations has noted a risk in the ageing of populations in such countries as e.g. Europe, Australia, North America, New Zealand, and Japan [1]. The percentage of the population over 65 years of age will rise in these countries over the next 15 years. Whereas in 2010, in a group of 100 people, 30 belonged to the age group of 25 - 64 years, by 2030 this number will climb to 46 [1]. Given this situation, the question evolves how owning a dog can help promote independence and health among the elderly.

Friedmann noted a significant reduction in the mortality of patients with chronic heart disease [2] [3], and Ruzic demonstrated that regular dog-walking improved physical capacity [4]. Dog ownership is credited with lowering blood pressure [5]-[9] and resting heart rate [8], a phenomenon which is intensified when a dog is pet [10]. The variability in heart rate rose significantly [11] and a prophylactic effect for heart health (evidence level B) was confirmed [12].

Regular, moderate exercise several times per week plays an essential role in preventive healthcare [13]-[15]. However, the percentage of people over the age of 60 in Germany who were inactive in 2012 was $34 \%$ for men and $40 \%$ for women [16]. In the European average, 59\% of women and $53 \%$ of men over the age of 55 are never physically active [17], in Australia, just under one third [18], in the USA more than 35\% [19].

\section{Material and Methods}

The survey was conducted of residents over 65 years of age in a rural community, Sauerlach, near Munich. Participants were acquired by means of a call to the public.

From Feb. 23rd to June 6th 2012, fifty-two persons (Table 1) took part in the study and were interviewed personally.

Cat owners were allocated to the group of people who did not own a dog. Due to the major difference between dog and cat owners, the analysis of cat owners is added as a separate text passage following the analysis of dog owner and those who do not own a dog.

In a one-on-one interview based on a questionnaire, participants were interviewed at home about their lifestyle, quality of life, social life, weight, height and various complaints and diagnoses. The BMI (Body-Mass Index) was also calculated.

Using the W-5 from the WHO [20], depressive symptoms were determined, a score below 13 points or 52\% can indicate depression.

Statistical calculations, e.g. the t Test were conducted using http://graphpad.com/quickcalcs and the Pearson correlation with the help of Microsoft Excel and the online calculator at http://vassarstats.net.

\section{Results}

\subsection{Age}

Dog owners were on average 70 years old (median age $69, \pm 4.16$ ), those who did not own a dog were 72 years old (median age $71, \pm 5.4$ ). Those who owned a cat exclusively were between 66 and 69 years old (median age $67 \pm 1.4)$.

Participants were not asked to give their socio-economic status; the majority live in their own home and have a high standard of living.

Table 1. Distribution of the 52 participants among the sub-groups $(\mathrm{N}=52)$.

\begin{tabular}{cccc}
\hline & Men & Women & Total \\
\hline Dog owner & 8 & 8 & $\mathbf{1 6}$ \\
No dog (including cat owners) & 18 & 18 & $\mathbf{3 6}$ \\
No dog, but cat owner & 2 & 3 & $\mathbf{5}$ \\
Total & 26 & 26 & $\mathbf{5 2}$ \\
\hline
\end{tabular}




\subsection{Pros and Cons of Dog Ownership, Difficulties}

Dog owners $(\mathrm{N}=16)$ stated as the most frequent reason for having a dog was that they liked having an animal to take care of $(75 \%, N=12)$, they had a reason to leave the house $(69 \%, N=11)$, they had contact to other people through the animal $(38 \%, \mathrm{~N}=6)$, and they had a pet as a substitute for children $(35 \%, \mathrm{~N}=4) .19 \%$ kept the dog for protection $(\mathrm{N}=3)$; another $19 \%(\mathrm{~N}=3)$ stated other reasons. One person had a dog to keep from being alone $(6 \%, N=1)$.

3 of 5 cat owners kept the cat as a substitute for children. The cat was referred to once as a "watchcat" in case something happens to the owner, once as company, and once as a being that one can take care of.

Among those who did not own a dog, the most frequent reason for not having a dog was the desire not to be tied down. This is the reason why cat owners were factored out of the assessment. 24 of 36 participants from the group of those who do not have a dog were able to state a specific reason for not having a dog (Table 2). Other pets were not kept.

Other individual opinions:

- “The dog is not properly exercised because it is always on leash".

- "No dog because of responsibility, ethics and legal restrictions".

- “Don't want an animal”.

- "A dog is a luxury, large dogs are trendy just like large cars”.

- "I grew up on a farm and had no childhood because I always had to take care of the animals".

$50 \%(\mathrm{~N}=8)$ of the dog owners said they had no problem taking care of the dog. $38 \%(\mathrm{~N}=6)$ had no one to take over if they weren't able. One participant mentioned the financial burden and trouble with the environment (neighbors, authorities, etc.) $(6 \%, \mathrm{~N}=1)$, another only felt a financial burden $(6 \%, \mathrm{~N}=1)$.

$100 \%$ of the cat owners $(\mathrm{N}=5)$ considered the only difficulty of having a cat the problem of finding someone to take care of the animal in the event of their inability to do so.

\subsubsection{Dealing with the Dog and Loss of the Dog}

All dog owners participated $(\mathrm{N}=16)$. Walking was the most frequent and most important activity undertaken with the dog (88\% of the women and $100 \%$ of the men), also petting, scratching and rubbing the dog (63\% of the women and $50 \%$ of the men) and playing with the dog (38\% women, 50\% men) were also mentioned. $38 \%$ of both sexes also talked to the dog.

The most important activity undertaken with the cat was petting, scratching and rubbing for $100 \%$ of the participants, followed by talking to and playing with it $80 \%$.

The dog slept in the bedroom of $50 \%(\mathrm{~N}=8), 38 \%(\mathrm{~N}=6)$ shared a bed with the dog. Cats slept in the bed of $80 \%$ of their owners.

In the event of a loss of a dog, $50 \%(\mathrm{~N}=8)$ indicated they would get another dog. The ratio of men:women was $5: 3$, the average age was 68 (median $67.5, \pm 2.6$ ). In the group that rejected the idea of getting another dog, the ratio of men:women was 3:5. The average age was 72 (median $71 \pm 4.7$ ).

Only $40 \%$ of the cat owners wanted to get another cat in the event of a loss.

Table 2. Reasons not to have a dog in the group of those who do not have a $\operatorname{dog}(\mathrm{N}=24)$ (multiple answers permitted).

\begin{tabular}{cc}
\hline & Total \\
\hline Tied down & $50 \%(\mathrm{~N}=12)$ \\
Travel/holidays & $25 \%(\mathrm{~N}=6)$ \\
Avoid pain of loss & $12.5 \%(\mathrm{~N}=3)$ \\
No time because of work & $12.5 \%(\mathrm{~N}=3)$ \\
Not hygienic & $4 \%(\mathrm{~N}=1)$ \\
Partner does not want a dog & $4 \%(\mathrm{~N}=1)$ \\
Might outlive me & $4 \%(\mathrm{~N}=1)$ \\
More work & $8 \%(\mathrm{~N}=2)$ \\
\hline
\end{tabular}




\subsubsection{Dog and Death of Someone Close}

$43 \%$ of the dog owners $(N=7)$ already had the dog when a close friend or relative died. For $71 \%(N=5)$ the dog helped overcome the pain of loss. $40 \%$ of the cat owners stated that having a cat was a help in this situation.

\subsection{Maintaining Independence}

\section{Dog and Move to a Long-Term Care/Nursing or Retirement Facility}

$63 \%$ of the participants would not move to another apartment or home because of the dog; $80 \%$ would decide not to move to a retirement home/assisted living because of the dog and $87 \%$ would want to take the dog with them if forced to move to a retirement home or similar facility.

One participant categorically ruled out a move to a retirement home so that she was not able to be evaluated for this response.

$20 \%$ of the cat owners would not move to another apartment or home because of the cat; $80 \%$ would decide not to move to a retirement home/assisted living because of the cat and all of them would want to take the cat with them if they had to move to a care facility.

\subsection{Comparison of the Social Situation of the Groups}

\subsubsection{Dog Ownership and Partnership}

All participants lived in their own households, $88 \%$ of the dog owners and $75 \%$ of those without a dog were married or cohabited. Among the 52 participants were 14 married couples (54\%). 10 of these had no pets, 3 had a dog and 1 couple had a cat. $80 \%$ of the cat owners had a partner.

In regard to the size of the circle of acquaintances, there was no difference between the groups with dog and no dog.

\subsubsection{Social Contacts with the Outside World}

When asked about daily contact to other people, a chance meeting e.g. at the mailbox was also taken into account. $50 \%$ of the dog owners, $41 \%$ of those who do not own a dog and $40 \%$ of the cat owners had more than 3 encounters daily. $6 \%$ of the dog owners, $23 \%$ of those who do not own a dog and $60 \%$ of the cat owners had on average fewer than one encounter per day with other people.

Conversations on the street regularly developed in both groups (dog owners and those who do not own a dog), $81 \%$ of the dog owners said that the dog helped make contact to other people. $19 \%$ of the dog owners, $36 \%$ of those who do not have a dog, and $40 \%$ of the cat owners considered themselves reserved in dealings with other people.

\subsection{Comparison of the Independence of the Groups}

\section{Mobility and Transportation Used}

Mobility is an important part of an autonomous life. It was recorded based on the mode of transportation used. Three participants had never had a driver's license, one person in the dog group and two in the no-dog group. In regard to cycling, frailty and lack of motivation were the reasons given for not riding a bicycle. The distribution of the groups you can see in Figure 1.

$60 \%$ of the cat owners drove, $80 \%$ cycled and $100 \%$ used public transportation.

\subsection{Comparison of the Physical Activity of the Groups}

\subsubsection{Frequency and Duration of the Walks}

$94 \%$ in both groups took regular walks. The frequency per week was broken down for the day. For example, "three times per week" was calculated as a frequency of 0.42 times per day. Likewise the cumulative duration for several walks per day and the distance covered was broken down for the day. Statements such as "between 60 and 120 minutes” were averaged to 90 minutes. Figure 2 shows that dog owners walk daily significant more and longer than non dog owners.

There was no significant correlation between the participants' BMI (calculated based on the information provided by the participants regarding height and weight) and the daily walk duration as stated in the case history ( $p>0.01$ ). $40 \%$ of the cat owners did not walk at all, 60\% walked between 60 and 150 minutes per week, cor- 


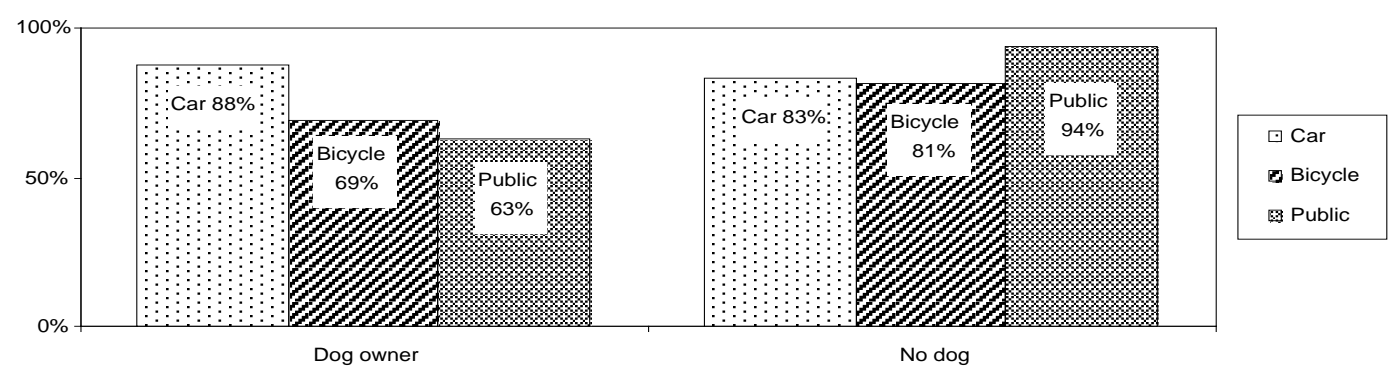

Figure 1. Use of mode of transport depending on dog ownership. Participants in percentage $(\mathrm{N}=52)$, multiple answers permitted.
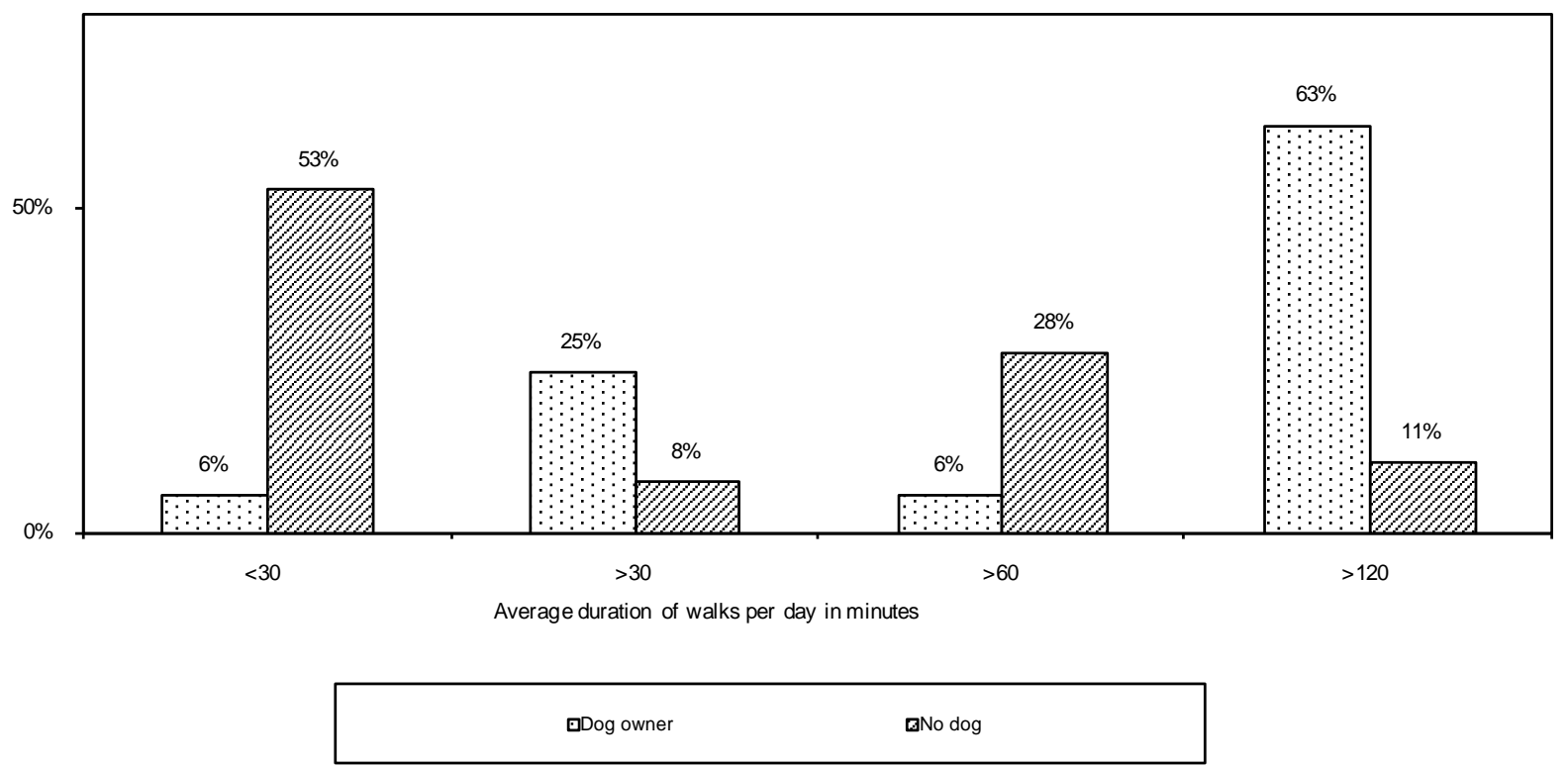

Figure 2. Daily average walk duration in minutes. A comparison of dog owners and those who do not own a dog, participants in percentage $(\mathrm{N}=51)$. $\mathrm{T}$ test $\mathrm{t}=5.9232 \mathrm{df}=50 \pm 14.212, \mathrm{CI}=95 \%, \mathrm{p}<0.0001$.

responding to an average 17.14 minutes per day (median 21.43, \pm 7.42 ). Table 3 shows the details.

Dog owners between the ages of 65 and 75 walked on average approx. 840 minutes/week; dog owners between 71 and 79 walked 588 minutes $( \pm 449)$, those who do not own dogs 299 minutes $( \pm 226)$. There was no correlation between the age of the dog owners and those who do not own a dog and the duration of the daily walks $(r=0.078, \mathrm{p}>0.1)$.

\subsubsection{Sports Activities}

In both groups, the types of sports, namely, swimming, hiking, (aqua) aerobics, cycling were equally distributed; jogging, (Nordic) walking, yoga, competitive dancing, weight training, downhill skiing were pursued exclusively by those who do not own a dog. Table 4 shows frequency and social integration in regard to the pursuit of sports activities. Overall physical activity including dog walking you can see in Figure 3.

$40 \%$ of the cat owners stated that they did no sports whatsoever; $60 \%$ do some kind of sport several times per week alone or with a single sports partner.

\subsection{Comparison of the Need for Medical Care, Morbidity}

\subsubsection{BMI}

In the dog group, the average BMI (calculated based on the information provided by the participants regarding height and weight) was $25.3 \mathrm{~kg} / \mathrm{m}^{2}$ (median 24.97, \pm 2.7 ), in the no dog group $25.6 \mathrm{~kg} / \mathrm{m}^{2}$ (median 24.4, \pm 4.02 ). Among dog owners who do take walks (15 of 16), the BMI was on average $25 \mathrm{~kg} / \mathrm{m}^{2}$ (median 24.8, \pm 2.7 ), for 
Table 3. Comparison of the groups dog and no dog in relation to daily average walk duration, frequency and distance covered $(\mathrm{N}=52)$.

\begin{tabular}{|c|c|c|}
\hline & Dog & No Dog \\
\hline Walk frequency per day on average & Ǿ 2.7 times & Ǿ 0.94 times \\
\hline Frequency per day median $( \pm)$ & $3.0( \pm 1.40)$ & $0.75( \pm 0.74)$ \\
\hline Frequency per week median $( \pm)$ & $17.5( \pm 10.54)$ & $3.5( \pm 4.31)$ \\
\hline More than once per day & $\mathrm{N}=11$ & $\mathrm{~N}=5$ \\
\hline Once per day & $\mathrm{N}=4$ & $\mathrm{~N}=12$ \\
\hline Less than once per day & $\mathrm{N}=0$ & $\mathrm{~N}=14$ \\
\hline No walks & $\mathrm{N}=1$ & $\mathrm{~N}=5$ \\
\hline Number total & $N=16$ & $\mathbf{N}=36$ \\
\hline Daily walk duration on average & $122 \mathrm{~min}$ & $38 \mathrm{~min}$ \\
\hline Median ( \pm ) & $120 \min ( \pm 62)$ & $21 \min ( \pm 39)$ \\
\hline Weekly walk duration on average & $854 \min$ & $267 \mathrm{~min}$ \\
\hline Median $( \pm)$ & $840 \min ( \pm 436)$ & $150 \min ( \pm 274)$ \\
\hline
\end{tabular}

Table 4. Comparison of frequency and social integration in regard to the pursuit of sports activities-multiple answers permitted.

\begin{tabular}{lcc}
\hline & Dog $(\mathbf{N}=\mathbf{1 6})$ & No dog (N = 36) \\
\hline Daily sports & $\mathrm{N}=1(6 \%)$ & $\mathrm{N}=5(14 \%)$ \\
Sports several times per week & $\mathrm{N}=9(56 \%)$ & $\mathrm{N}=18(50 \%)$ \\
Alone or with a single sports partner & $\mathrm{N}=8(50 \%)$ & $\mathrm{N}=23(64 \%)$ \\
Group sports & $\mathrm{N}=8(80 \%)$ & $\mathrm{N}=17(47 \%)$ \\
Percentage total & $81 \%$ & $75 \%$ \\
BMI & 25.8 & 25.4 \\
\hline
\end{tabular}

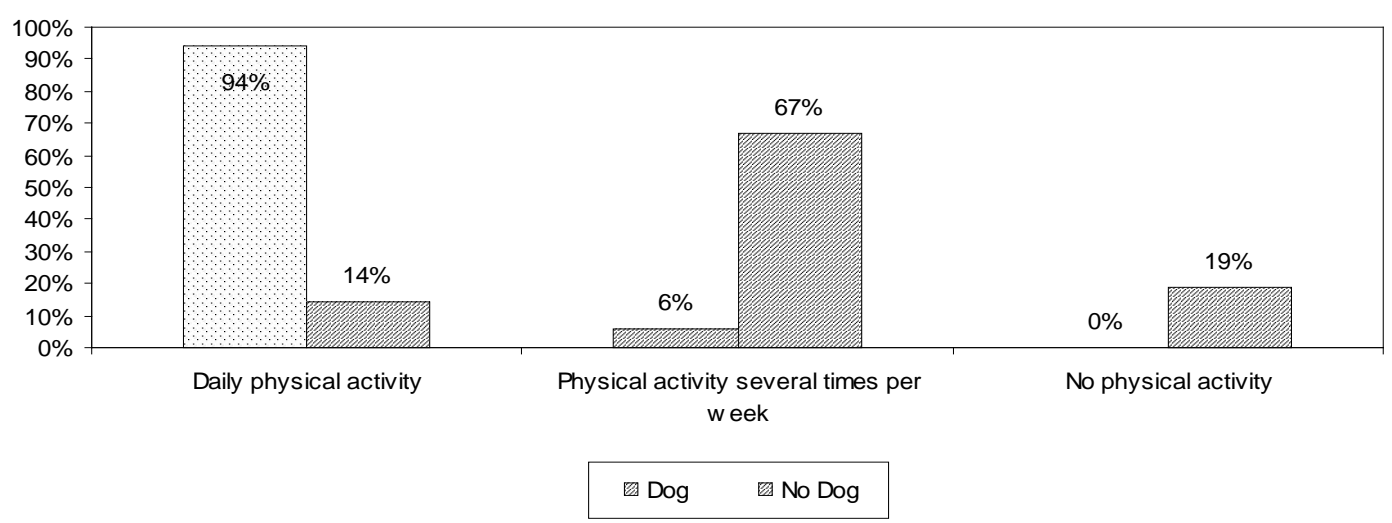

Figure 3. Frequency of physical activity (sports + daily walks of 30 minutes or longer); dog group compared to no-dog group. Participants in percentage $(\mathrm{N}=52)$.

the person who did not walk, $26 \mathrm{~kg} / \mathrm{m}^{2}$.

Those who do not own a dog whose weekly walk duration was less than 150 minutes were evaluated as "nonwalkers”. Their average BMI was $26.1 \mathrm{~kg} / \mathrm{m}^{2}$ (median 24.4, \pm 4.02 ), that of the "walker" $25.4 \mathrm{~kg} / \mathrm{m}^{2}$ (median $25.6, \pm 4.56)$. A statistical correlation of duration of walk to BMI was not established $(r=0.1, p>0.1)$. Figure 4 


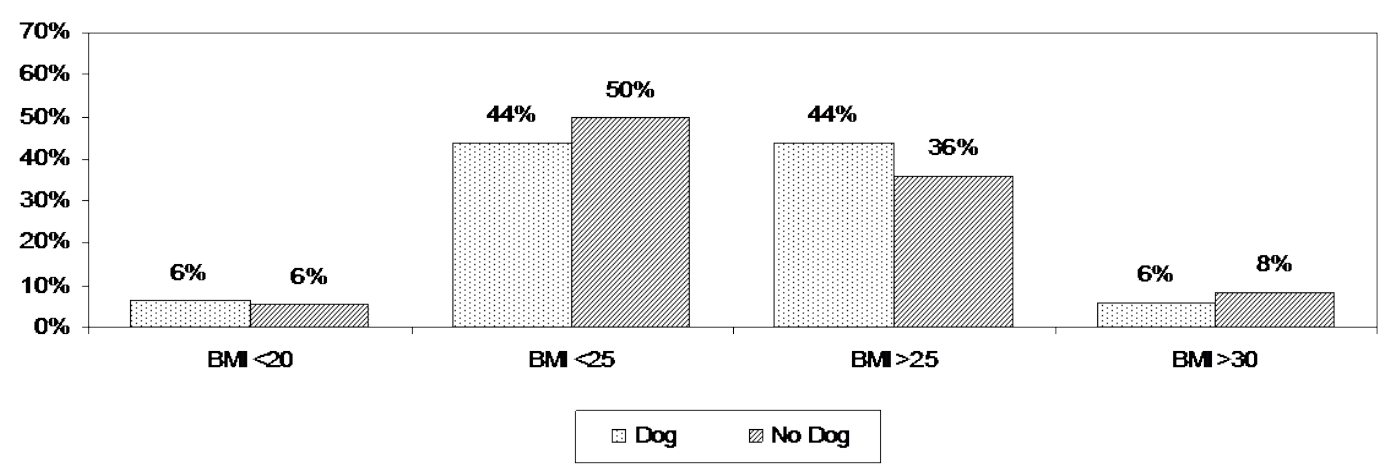

Figure 4. BMI dog owners compared to those who do not own a dog. Participants in percentage $(\mathrm{N}=52)$,

T test $\mathrm{t}=0.0906, \mathrm{p}>0.1$.

shows the distribution of the BMI between dog owners and non dog owners.

Cat owners had an average BMI of $25.3 \mathrm{~kg} / \mathrm{m}$ ” (median 24.s9, \pm 2.1 ).

\subsubsection{Frequent Symptoms and Diagnoses}

In Table 5, we can see the incidence of frequent symptoms and diagnoses in the two groups, shown in percentage.

$20 \%$ of the cat owners had a fear of the future, $20 \%$ hay fever, $80 \%$ back pain, $60 \%$ joint pain and $40 \%$ foot complaints, $20 \%$ had sinus problems, $20 \%$ coronary heart disease, $40 \%$ arterial hypertension and $40 \%$ impaired mobility.

\subsubsection{Frequency of Medical Consultation}

All visits to doctors with the exception of dentist and gynecologist were evaluated. Dog owners went on average 5.3 times per year and person to the doctor; those who do not own a dog 7.8 times per year and person. The general practitioner (1.2 times dog owner, 1.6 times no-dog) and the internist (2 times dog owner, 1.9 times no-dog) were consulted most frequently. The remaining medical consultations were distributed among various specialists.

\subsubsection{The Taking of Medication}

In the dog group, $69 \%(\mathrm{~N}=11)$ regularly take medication and/or vitamins, in the no-dog group $83 \%(\mathrm{~N}=30)$. Vitamin K antagonists, antihypertensives, antidiabetics, lipid reducers, platelet inhibitors and psychotropic drugs (e.g. benzodiazepines and antidepressants). ASS was considered a platelet inhibitor. Multiple antihypertensive therapies were counted as one drug per person. Alpha-1 and 1a antagonists for benign prostatic hyperplasia and homeopathy were not considered as was the use of PPI (proton pump inhibitors).

Two individuals (who are not dog owners) took antidepressants, were not considered because of traumatic experiences in the recent past. Figure 5 shows the medication intake compared between dog owners and non dog owners.

\subsection{Vigor and Vitality}

The W-5 from the WHO was used to record subjective welfare and wellbeing. Three participants (no dog) were excluded from the evaluation of this question due to traumatic life experiences in the recent past. Table 6 shows details.

2 dog owners and 4 individuals who do not have a dog had a score of less than 13 points $(=52 \%$, indication of depression), corresponding in both groups to $12 \%$.

In response to the question "Is your day full of things that interest you", many women answered that they were not interested in daily housework and consequently many only gave 3 or 4 points instead of a possible 5 . This was the most frequent reason for the lower number of points among women.

In regard to alcohol consumption, the groups did not differ. Daily consumption was $50 \%$ in both groups. In the dog group, $13 \%$ of the men and women smoked, and in the no-dog group $6 \%$ of the women and no men. 
Table 5. Comparison of the groups in regard to frequent symptoms and diagnoses. Information in percentage. $\mathrm{N}=52$.

\begin{tabular}{|c|c|c|}
\hline & Dog owners $N=16$ & Those who do not own a dog $N=36$ \\
\hline Depression & $0 \%$ & $6 \%$ \\
\hline Sleep-onset insomnia & $19 \%$ & $6 \%$ \\
\hline Sleep-maintenance insomnia & $20 \%$ & $12 \%$ \\
\hline Fear of the future & $0 \%$ & $12 \%$ \\
\hline Headache & $0 \%$ & $3 \%$ \\
\hline Hay fever & $6 \%$ & $6 \%$ \\
\hline Back pain & $25 \%$ & $31 \%$ \\
\hline General fatigue & $0 \%$ & $8 \%$ \\
\hline Kidney and bladder conditions & $13 \%$ & $3 \%$ \\
\hline Joint pain & $19 \%$ & $31 \%$ \\
\hline Foot complaints & $6 \%$ & $8 \%$ \\
\hline Irregular heart beat/shortness of breath & $0 \%$ & $3 \%$ \\
\hline Indigestion & $0 \%$ & $6 \%$ \\
\hline Sinus complaints & $13 \%$ & $8 \%$ \\
\hline Chronic cough & $13 \%$ & $0 \%$ \\
\hline Asthma & $0 \%$ & $8 \%$ \\
\hline Cardiovascular disease, atrial fibrillation & $19 \%$ & $17 \%$ \\
\hline Arterial hypertension & $44 \%$ & $39 \%$ \\
\hline Condition following Apoplex (stroke) & 0 & $3 \%$ \\
\hline Dizziness & $6 \%$ & $3 \%$ \\
\hline Vision problems & $19 \%$ & $14 \%$ \\
\hline Hearing problems & $6 \%$ & $8 \%$ \\
\hline Liver diseases & $13 \%$ & $3 \%$ \\
\hline Digestion problems & $0 \%$ & $3 \%$ \\
\hline Diabetes mellitus & $19 \%$ & $6 \%$ \\
\hline Neuropathies & $0 \%$ & $11 \%$ \\
\hline Peripheral arterial disease & $6 \%$ & $3 \%$ \\
\hline Impaired mobility & $6 \%$ & $3 \%$ \\
\hline
\end{tabular}

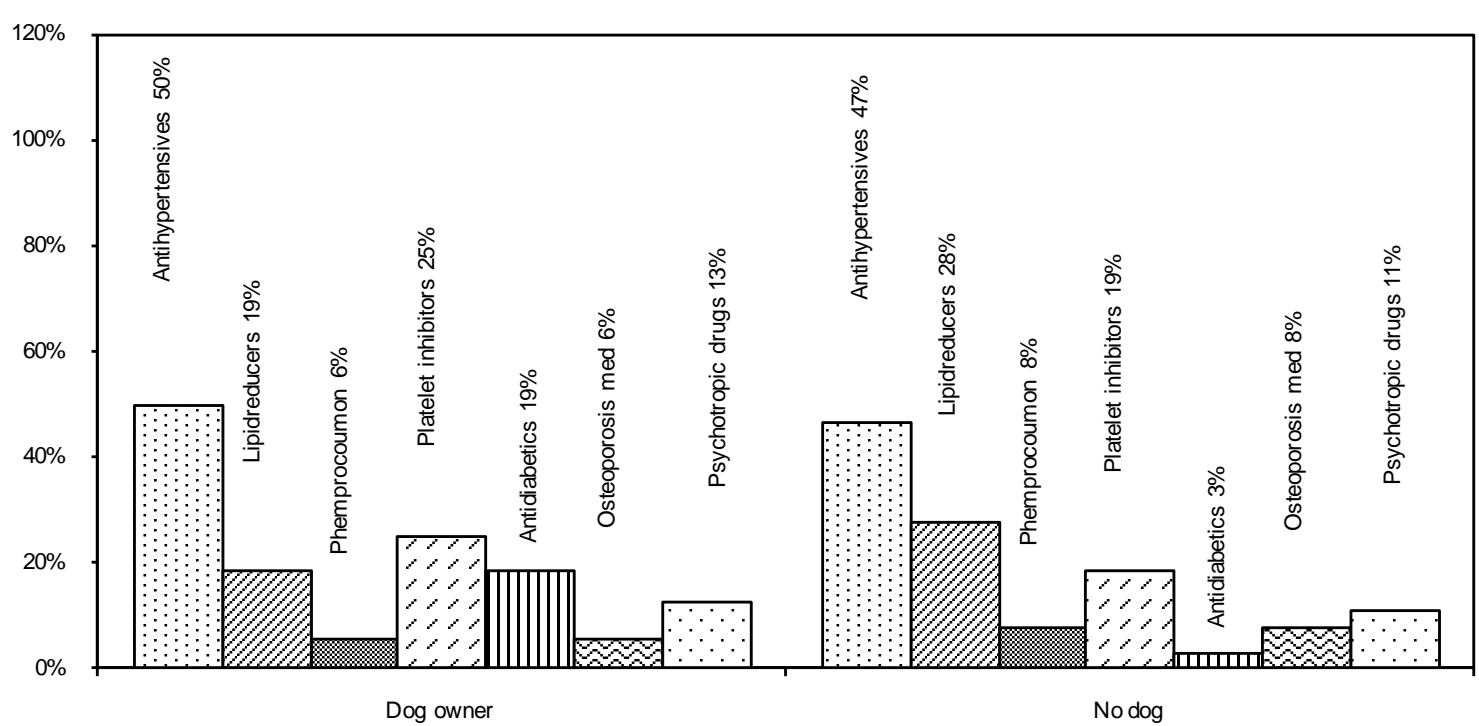

Figure 5. Medication intake dog (owner) and no dog. Participants in percentage $(\mathrm{N}=50)$. 
Table 6. Comparison average wellbeing five score dog and no dog in percentage $(\mathrm{N}=49)$.

\begin{tabular}{cccc}
\hline \multicolumn{2}{c}{ Dog owner average 75\% of which } & \multicolumn{2}{c}{ No dog average $71 \%$ of which } \\
\hline Women $73 \%$ & Men $78 \%$ & Women $66 \%$ & Men $74 \%$ \\
\hline
\end{tabular}

\section{Discussion}

Prior to conducting the study, it was expected that dog owners would be the more active, healthier participants. Surprisingly, those who do not own dogs appear to be in some cases healthier and more vital; they reject dog ownership to maintain their personal freedom and to stay flexible. Raina confirms this phenomenon [21], Burns also mentions economic reasons [22].

The present study makes no claim to general validity, but is a random sampling to compare with other studies. Weaknesses in the present study are the number of participants $(n=52)$ and the collection of data provided by participants during an interview. Many authors have also mentioned these problems [23]-[28].

Dog owners who walk their dogs got significantly more exercise which confirms studies of dogs and the elderly [23] [29]-[36], but also of dogs and people of all ages [7] [23] [37]-[46]. The dog owners in this study exceeded by far the WHO recommendations for people over the age of 65 in regard to physical activity to maintain health by an average of 2.5 hours (=150 minutes) of physical activity or more per week [15]. Australian studies challenge the connection between dog ownership and the resulting health benefits [47] [48]. The Australian lifestyle seems to be different than in Germany and it is less usual to walk with the dog.

A lack of exercise is a widespread health risk in industrialized countries. The increase in movement due to the dog is an important prophylaxis against cardiovascular diseases [49], which is a frequent reason for hospitalizations [50]. Movement also prevents diabetes, intestinal cancer and age-related falls [51] and even has a positive effect on arthrosis [52].

One explanation for the strong effect of the dog on the owner's physical activity could be that Germany is densely populated and life is extensively regulated and the dog in more populated regions must be walked on a leash during the multiple daily walks. Consequently, the impact of a dog on the owner's physical activity in Germany is to be rated as especially intensive in an international comparison. In this respect, it was clear that dog owners and cat owners cannot be compared, as confirmed by Thrope and Serpell [23] [46] [53] so that a comparison of pet owner and those who do not have a pet does not appear to make much sense without differentiation of the type of pet.

The statements on the subject of a move to an assisted living facility were very clear. A move would only be considered if the dog or cat could be taken along.

In this case, more offerings should be made available in the retirement home sector for residents with dog and other pets to provide those affected with alternatives, particularly if owners are overwhelmed by the care of the pet because of their frailty or dementia and an attempt to provide care would jeopardize the owner and/or the animal. This could allow pet owners to keep their "friend" and still go to a care environment.

Dog owners had on average more internal medicine diagnoses and took just as much medication as those who did not own a dog; back and joint pain was less frequent, as Serpell also confirms [54]; the quality of life was higher on average, even though the percentage of depressed individuals was just as high as among those who did not own a dog. Friedmann discovered more depressed individuals in the group of those who did not own dogs [55]. Other studies noted a higher level of satisfaction and stability among dog owners [36] and fears were significantly lower [46]. Dog owners feel significantly safer with the dog [56].

These positive mental effects could be based on the intensive connection to the dog. This tie is closer than to other pets as indicated by the selection of the place to sleep and how the dog is treated. This was also described by other authors [56] [57]. In the event of a death, the dog was a comfort to the majority, which confirmed the results of Akiyama [58].

Dog owners went to the doctor much less frequently; in Siegel, the comparison of dog owners to those with no dog was significant. The comparison of pet owners to dog owners was not [56] [59].

Dog owners also had more frequent contact to the social environment and were less reserved than those who did not own a dog. The dog was an effective catalyst to establish contact, which other authors also described [36] [46] [60]. Good social ties are extremely important, particularly at an advanced age. The larger the social network is, the less loneliness and the less mental decline [61] which is encouraged by loneliness and social isola- 
tion are [62].

The positive effect of a dog could have positive effects from a national economic point of view because cardiovascular health is an important predictor of independence and health into old age.

Much research has been done on the subject "pets and the elderly", but little attention has been given to the topic "dogs and the elderly". The difference between a dog and other pets is so great that pet owners and those who do not own pets are not comparable. Additional research needs to be done, if possible with larger study groups or the question of the connection between dog ownership and hospitalizations and long-term studies dealing with the need for care in later life.

\section{Acknowledgements}

The published results are part of the thesis by Anne Poestges "Einfluss eines Haustieres auf körperliche Aktivität, Selbständigkeit, soziale Einbindung, Gesundheit und Lebensqualität älterer Menschen am Beispiel des Hundes” at the Medical Faculty of the Ludwig-Maximilians University of Munich (submitted).

\section{References}

[1] (2016). World Population Prospects: The 2015 Revision, Custom Data Acquired via Website [Internet]. http://esa.un.org/unpd/wpp/DataQuery/.

[2] Friedmann, E. and Thomas, S.A. (1995) Pet Ownership, Social Support, and One-Year Survival After Acute Myocardial Infarction in the Cardiac Arrhythmia Suppression Trial (CAST). American Journal of Cardiology, 76, 1213-1217. http://dx.doi.org/10.1016/S0002-9149(99)80343-9

[3] Friedmann, E., Katcher, A.H., Lynch, J.J. and Thomas, S.A. (1980) Animal Companions and One-Year Survival of Patients after Discharge from a Coronary Care Unit. Public Health Reports, 95, 307-312.

[4] Ruzic, A., Miletic, B., Ruzic, T., Persic, V. and Laskarin, G. (2011) Regular Dog-Walking Improves Physical Capacity in Elderly Patients after Myocardial Infarction. Collegium Antropologicum, 35, 73-75.

[5] Friedmann, E., Katcher, A.H., Thomas, S.A., Lynch, J.J. and Messent, P.R. (1983) Social Interaction and Blood Pressure. Influence of Animal Companions. The Journal of Nervous and Mental Disease, 171, 461-465. http://dx.doi.org/10.1097/00005053-198308000-00002

[6] Baun, M.M., Bergstrom, N., Langston, N.F. and Thoma, L. (1984) Physiological Effects of Human/Companion Animal Bonding. Nursing Research, 33, 126-129. http://dx.doi.org/10.1097/00006199-198405000-00002

[7] Lentino, C., Visek, A.J., McDonnell, K. and DiPietro, L. (2012) Dog Walking is Associated with a Favorable Risk Profile Independent of a Moderate to High Volume of Physical Activity. Journal of Physical Activity and Health, 9, 414-420.

[8] Kingwell, B.A., Lomdahl, A. and Anderson, W.P. (2001) Presence of a Pet Dog and Human Cardiovascular Responses to Mild Mental Stress. Clinical Autonomic Research, 11, 313-317. http://dx.doi.org/10.1007/BF02332977

[9] Anderson, W.P., Reid, C.M. and Jennings, G.L. (1992) Pet Ownership and Risk-Factors for Cardiovascular-Disease. Medical Journal of Australia, 157, 298-301.

[10] Vormbrock, J. and Grossberg, J. (1988) Cardiovascular Effects of Human-Pet Dog Interactions. Journal of Behavioral Medicine, 11, 509-517. http://dx.doi.org/10.1007/BF00844843

[11] Motooka, M., Koike, H., Yokoyama, T. and Kennedy, N.L. (2006) Effect of Dog-Walking on Autonomic Nervous Activity in Senior Citizens. Medical Journal of Australia, 184, 60-63.

[12] Levine, G.N., Allen, K., Braun, L.T., Christian, H.E., Friedmann, E., Taubert, K.A., et al. (2013) Pet Ownership and Cardiovascular Risk: A Scientific Statement from the American Heart Association. Circulation, 127, 2353-2363. http://dx.doi.org/10.1161/CIR.0b013e31829201e1

[13] Nelson, M.E., Rejeski, W.J., Blair, S.N., Duncan, P.W., Judge, J.O., King, A.C., et al. (2007) Physical Activity and Public Health in Older Adults: Recommendation from the American College of Sports Medicine and the American Heart Association. Medicine and Science in Sports and Exercise, 39, 1435-1445. http://dx.doi.org/10.1249/mss.0b013e3180616aa2

[14] Haskell, W.L., Lee, I.-M., Pate, R.R., Powell, K.E., Blair, S.N., Franklin, B.A., et al. (2007) Physical Activity and Public Health: Updated Recommendation for Adults from the American College of Sports Medicine and the American Heart Association. Circulation, 116, 1081-1093.

[15] World Health Organisation (2010) Global Recommendations on Physical Activity for Health, Geneva.

[16] Lampert, T., Mensink, G. and Müters, S. (2012) Körperlich-sportliche Aktivität bei Erwachsenen in Deutschland. 
Bundesgesundheitsblatt, Gesundheitsforschung, Gesundheitsschutz, 55, 102-110. http://dx.doi.org/10.1007/s00103-011-1401-3

[17] Sport and Physical Activity [Internet] (2014) http://ec.europa.eu/public_opinion/archives/ebs/ebs_412_fact_de_en.pdf

[18] Australian Government (2013) Australian Health Survey: Physical Activity 2011-12, Table 4: Sufficient Physical Activity, Ensure by Selected Population Characteristics, Persons Aged 18 Years and over [Internet]. http://www.abs.gov.au/AUSSTATS/abs@.nsf/DetailsPage/4364.0.55.0042011-12?OpenDocument

[19] Physical Activity Council (2016) 2016 Participation Report.

[20] WHO Regional Office for Europe (1998) Wellbeing Measures in Primary Health Care/The Depcare Project. Copenhagen, Denmark WHO Regional Office for Europe, Report on a WHO Meeting, Stockholm, 12-13 February.

[21] Raina, P., Waltner-Toews, D., Bonnett, B., Woodward, C. and Abernathy, T. (1999) Influence of Companion Animals on the Physical and Psychological of Older People: An Analysis of a One-Year Longitudinal Study. Journal of the American Geriatric Society, 47, 323-329. http://dx.doi.org/10.1111/j.1532-5415.1999.tb02996.x

[22] Burns, K. (2012) Survey Identifies Barriers to Pet Ownership: Top Reasons for Not Owning a Dog or Cat. Journal of the American Veterinary Medical Association, 241, 980-1012.

[23] Thorpe Jr., R.J., Simonsick, E.M., Brach, J.S., Ayonayon, H., Satterfield, S., Harris, T.B., et al. (2006) Dog Ownership, Walking Behavior, and Maintained Mobility in Late Life. Journal of the American Geriatric Society, 54, 1419-1424. http://dx.doi.org/10.1111/j.1532-5415.2006.00856.x

[24] Parslow, R.A. and Jorm, A.F. (2003) Pet Ownership and Risk Factors for Cardiovascular Disease: Another Look. Medical Journal of Australia, 179, 466-468.

[25] Headey, B. (2003) Pet Ownership: Good for Health? Medical Journal of Australia, 179, 460-461.

[26] Chur-Hansen, A., Stern, C. and Winefield, H. (2010) Commentary: Gaps in the Evidence about Companion Animals and Human Health: Some Suggestions for Progress. International Journal of Evidence-Based Healthcare, 8, 140-146. http://dx.doi.org/10.1111/j.1744-1609.2010.00176.x

[27] Cutt, H., Giles-Corti, B., Knuiman, M. and Burke, V. (2007) Dog Ownership, Health and Physical Activity: A Critical Review of the Literature. Health Place, 13, 261-272. http://dx.doi.org/10.1016/j.healthplace.2006.01.003

[28] Alonso, Y. (1999) Effect of Pets on Human Health: Is There a Correlation? Gesundheitswesen, 61, 45-49.

[29] Garcia, D.O., Wertheim, B.C., Manson, J.E., Chlebowski, R.T., Volpe, S.L., Howard, B.V., et al. (2015) Relationships between Dog Ownership and Physical Activity in Postmenopausal Women. Preventive Medicine, 70, 33-38. http://dx.doi.org/10.1016/j.ypmed.2014.10.030

[30] Feng, Z., Dibben, C., Witham, M.D., Donnan, P.T., Vadiveloo, T., Sniehotta, F., et al. (2014) Dog Ownership and Physical Activity in Later Life: A Cross-Sectional Observational Study. Preventive Medicine, 66, 101-106. http://dx.doi.org/10.1016/j.ypmed.2014.06.004

[31] Aiba, N., Hotta, K., Yokoyama, M., Wang, G., Tabata, M., Kamiya, K., et al. (2012) Usefulness of Pet Ownership as a Modulator of Cardiac Autonomic Imbalance in Patients with Diabetes Mellitus, Hypertension, and/or Hyperlipidemia. American Journal of Cardiology, 109, 1164-1170. http://dx.doi.org/10.1016/j.amjcard.2011.11.055

[32] Gretebeck, K.A., Radius, K., Black, D.R., Gretebeck, R.J., Ziemba, R. and Glickman, L.T. (2012) Dog Ownership, Functional Ability, and Walking in Community Dwelling Older Adults. Journal of Physical Activity and Health, 10, 646-655.

[33] Shibata, A., Oka, K., Inoue, S., Christian, H., Kitabatake, Y. and Shimomitsu, T. (2012) Physical Activity of Japanese Older Adults Who Own and Walk Dogs. American Journal of Preventive Medicine, 43, 429-433. http://dx.doi.org/10.1016/j.amepre.2012.06.019

[34] Scheibeck, R., Pallauf, M., Stellwag, C. and Seeberger, B. (2011) Elderly People in many Respects Benefit from Interaction with Dogs. European Journal of Medical Research, 16, 557-563. http://dx.doi.org/10.1186/2047-783X-16-12-557

[35] Dembicki, D. and Anderson, J. (1996) Pet Ownership May Be a Factor in Improved Health of the Elderly. Journal of Nutrition for the Elderly, 15, 15-31. http://dx.doi.org/10.1300/J052v15n03_02

[36] Rogers, J., Hart, L.A. and Boltz, R.P. (1993) The Role of Pet Dogs in Casual Conversations of Elderly Adults. The Journal of Social Psychology, 133, 265-277. http://dx.doi.org/10.1080/00224545.1993.9712145

[37] Lail, P., McCormack, G. and Rock, M. (2011) Does Dog-Ownership Influence Seasonal Patterns of Neighbourhoodased Walking among Adults? A Longitudinal Study. BMC Public Health, 11, 148. http://dx.doi.org/10.1186/1471-2458-11-148

[38] Gillum, R.F. and Obisesan, T.O. (2010) Living with Companion Animals, Physical Activity and Mortality in a US National Cohort. International Journal of Environmental Research and Public Health, 7, 2452-2459. 
http://dx.doi.org/10.3390/ijerph7062452

[39] Oka, K. and Shibata, A. (2009) Dog Ownership and Health-Related Physical Activity among Japanese Adults. Journal of Physical Activity and Health, 6, 412-418.

[40] Coleman, K.J., Rosenberg, D.E., Conway, T.L., Sallis, J.F., Saelens, B.E., Frank, L.D., et al. (2008) Physical Activity, Weight Status, and Neighborhood Characteristics of Dog Walkers. Preventive Medicine, 47, 309-312. http://dx.doi.org/10.1016/j.ypmed.2008.05.007

[41] Cutt, H., Knuiman, M. and Giles-Corti, B. (2008) Does Getting a Dog Increase Recreational Walking? International Journal of Behavioral Nutrition and Physical Activity, 5, 17. http://dx.doi.org/10.1186/1479-5868-5-17

[42] Yabroff, K.R., Troiano, R.P. and Berrigan, D. (2008) Walking the Dog: Is Pet Ownership Associated with Physical Activity in California? Journal of Physical Activity and Health, 5, 216-228.

[43] Brown, S.G. and Rhodes, R.E. (2006) Relationships among Dog Ownership and Leisure-Time Walking in Western Canadian Adults. American Journal of Preventive Medicine, 30, 131-136. http://dx.doi.org/10.1016/j.amepre.2005.10.007

[44] Bauman, A., Russell, S., Furber, S. and Dobson, A. (2001) The Epidemiology of Dog Walking: An Unmet Need for Human and Canine Health. Medical Journal of Australia, 175, 632-634.

[45] Wells, Y. and Rodi, H. (2000) Effects of Pet Ownership on the Health and Well-Being of Older People. Australasian Journal on Ageing, 19, 143-148. http://dx.doi.org/10.1111/j.1741-6612.2000.tb00167.x

[46] Serpell, J. (1990) Evidence for Long Term Effects of Pet Ownership on Human Health. Pets, Benefits and Practice: Waltham Symposium 1990, Courtesy of Waltham, 19 April 1990, 1-7.

[47] Parker, G.B., Gayed, A., Owen, C.A., Hyett, M.P., Hilton, T.M. and Heruc, G.A. (2010) Survival Following an Acute Coronary Syndrome: A Pet Theory Put to the Test. Acta Psychiatrica Scandinavica, 121, 65-70. http://dx.doi.org/10.1111/j.1600-0447.2009.01410.x

[48] Pachana, N.A., Ford, J.H., Andrew, B. and Dobson, A.J. (2005) Relations between Companion Animals and Selfeported Health in Older Women: Cause, Effect or Artifact? International Journal of Behavioral Medicine, 12, 103-110. http://dx.doi.org/10.1207/s15327558ijbm1202_8

[49] Mensink, G.B.M., Deketh, M., Mul, M.D.M., Schuit, A.J. and Hoffmeister, H. (1996) Physical Activity and Its Association with Cardiovascular Risk Factors and Mortality. Epidemiology, 7, 391-397. http://dx.doi.org/10.1097/00001648-199607000-00009

[50] Nowossadeck, E. (2012) Population Aging and Hospitalization for Chronic Disease in Germany. Deutsches Ärzteblatt, 109, 151-157.

[51] Rütten, A., Karim, A.-O., Lampert, T. and Ziese, T. (2005) Körperliche Aktivität. In: Koch, B.R., Ed., Bundesministerium für Gesundheit und Soziale Sicherung, Institut in Zusammenarbeit mit dem Statistischen Bundesamt, 1-36.

[52] Schäfer, M. and Dreinhöfer, K. (2009) Sport und Arthrose. Zeitschrift für Rheumatologie, 68, 804-810. http://dx.doi.org/10.1007/s00393-009-0552-1

[53] Thorpe Jr., R.J., Kreisle, R., Glickman, L., Simonsick, E., Newman, A. and Kritchevsky, S. (2006) Physical Activity and Pet Ownership in Year 3 of the Health ABC Study. Journal of Aging and Physical Activity, 14, 154-168.

[54] Serpell, J. (1991) Beneficial Effects of Pet Ownership on Some Aspects of Human Health and Behaviour. Journal of the Royal Society of Medicine, 84, 717-720.

[55] Friedmann, E., Thomas, S.A., Stein, P.K. and Kleiger, R.E. (2003) Relation between Pet Ownership and Heart Rate Variability in Patients with Healed Myocardial Infarcts. American Journal of Cardiology, 91, 718-721. http://dx.doi.org/10.1016/S0002-9149(02)03412-4

[56] Siegel, J. (1990) Stressful Life Events and Use of Physician Services among the Elderly: The Moderating Role of Pet Ownership. Journal of Personality and Social Psychology, 58, 1081-1086. http://dx.doi.org/10.1037/0022-3514.58.6.1081

[57] Stallones, L., Marx, M.B., Garrity, T.F. and Johnson, T.P. (1988) Attachment to Companion Animals among Older Pet Owners. Anthrozoos, 2, 118-124. http://dx.doi.org/10.2752/089279389787058127

[58] Akiyama, H., Holtzman, J.M. and Britz, W.E. (1987) Pet Ownership and Health Status during Bereavement. OMEGA: Journal of Death and Dying, 17, 187-193. http://dx.doi.org/10.2190/8JWU-Q6JT-LL3P-MWW8

[59] Siegel, J. (1993) Companion animals: In Sickness and in Health. Journal of Social Issues, 49, 157-167. http://dx.doi.org/10.1111/j.1540-4560.1993.tb00915.x

[60] McNicholas, J. and Collis, G.M. (2000) Dogs as Catalysts for Social Interactions: Robustness of the Effect. British Journal of Social Psychology, 91, 61-70. http://dx.doi.org/10.1348/000712600161673

[61] Wilson, R.S., Krueger, K.R., Arnold, S.E., et al. (2007) Loneliness and Risk of Alzheimer Disease. Archives of Gener- 
al Psychiatry, 64, 234-240. http://dx.doi.org/10.1001/archpsyc.64.2.234

[62] Shankar, A., Hamer, M., McMunn, A. and Steptoe, A. (2013) Social Isolation and Loneliness: Relationships with Cognitive Function during 4 Years of Follow-Up in the English Longitudinal Study of Ageing. Psychosomatic Medicine, 75, 161-170. http://dx.doi.org/10.1097/PSY.0b013e31827f09cd

\section{Submit or recommend next manuscript to SCIRP and we will provide best service for you:}

Accepting pre-submission inquiries through Email, Facebook, LinkedIn, Twitter, etc.

A wide selection of journals (inclusive of 9 subjects, more than 200 journals)

Providing 24-hour high-quality service

User-friendly online submission system

Fair and swift peer-review system

Efficient typesetting and proofreading procedure

Display of the result of downloads and visits, as well as the number of cited articles

Maximum dissemination of your research work

Submit your manuscript at: http://papersubmission.scirp.org/ 